\title{
Awareness and Occupational Exposure to Brucellosis and Other Zoonotic Diseases Among Abattoir Workers in Rwanda
}

Jean Bosco Ntivuguruzwa ( $\sim$ boscus2@gmail.com )

Department of Veterinary Medicine, School of Veterinary Medicine, University of Rwanda, Nyagatare Anita Michel

Bovine Tuberculosis and Brucellosis Research Programme, Department of Veterinary Tropical Diseases, Faculty of Veterinary Science, University of Pretoria; Pretoria 0110, South Africa

Charles Byaruhanga

Bovine Tuberculosis and Brucellosis Research Programme, Department of Veterinary Tropical Diseases, Faculty of Veterinary Science, University of Pretoria; Pretoria 0110, South Africa

\section{Richard Gashururu}

Department of Veterinary Medicine, School of Veterinary Medicine, University of Rwanda, Nyagatare

\section{Francis Babaman Kolo}

Bovine Tuberculosis and Brucellosis Research Programme, Department of Veterinary Tropical Diseases, Faculty of Veterinary Science, University of Pretoria; Pretoria 0110, South Africa Henriette vanHeerden

Bovine Tuberculosis and Brucellosis Research Programme, Department of Veterinary Tropical Diseases, Faculty of Veterinary Science, University of Pretoria; Pretoria 0110, South Africa

\section{Research Article}

Keywords: abattoir workers, Brucella spp., Mycobacterium bovis, occupational exposure, zoonotic brucellosis, zoonotic tuberculosis, Rwanda

Posted Date: November 12th, 2021

DOI: https://doi.org/10.21203/rs.3.rs-1012737/v1

License: (c) (1) This work is licensed under a Creative Commons Attribution 4.0 International License. Read Full License 


\section{Abstract}

Background: Brucellosis and bovine tuberculosis are endemic in Rwandan cattle, but little is known about the awareness of zoonotic transmission and occupational exposure among abattoir workers.

Methods: A cross-sectional study was conducted to investigate the awareness, practices, and history of the diseases among 100 abattoir workers from four high throughput and 18 workers from two low throughput abattoirs. Data were collected by face-to-face interviews using a questionnaire, and exposure and outcome variables were assessed by univariate and correspondence analyses.

Results: It was found that $82.2 \%, 27.1 \%, 8.5 \%, 10.2 \%$, and $12.7 \%$ of abattoir workers were familiar with tuberculosis, brucellosis, Q-fever, leptospirosis, and cysticercosis, respectively. Three years before the survey, the majority (67.8\%) of abattoir workers reported sickness of malaria (48.3\%), and symptoms of flu $(5.1 \%)$, headache $(5.1 \%)$, fever $(5.1 \%)$, headache $(5.1 \%)$, and nephritis $(3.4 \%)$. Malaria-negative patients had the symptoms of fatigue (11.0\%), and flu (9.3\%). Respondents $(7.6 \%)$ had contracted 'abattoir-related diseases including typhoid (1.7\%) and have had symptoms of diarrhea (5.9\%). Few workers also reported abortion $(0.9 \%)$, and orchitis $(0.9 \%)$. Most abattoir workers $(70.3 \%)$ usually cut their hands, a few $(9.3 \%)$ wore gloves while $39.8 \%$ worked with bare and injured hands. Most $(74.6 \%)$ of workers experienced splashes of animal fluids into their faces while none $(0.0 \%)$ wore facemasks or safety goggles. Eating at work was observed in $28.0 \%$ of abattoir workers. Univariate and correspondence analyses showed that transporters of carcasses, butchers, and workers with 3 years' experience and above were more likely to get sick than other groups.

Conclusions: The awareness that was low for zoonotic brucellosis, Q-fever, leptospirosis, and cysticercosis was supported by not wearing protective equipment's alerting the competent veterinary authorities to improve biosafety protection in the abattoirs. The awareness for zoonotic brucellosis and tuberculosis was highest in educated workers indicating the need for educating abattoir. Abattoir workers reported the symptoms of fever, fatigue, flu, headache, nephritis, abortion, and orchitis which are common symptoms of brucellosis, leptospirosis, and Q-fever. Abattoirs are key points for the detection of zoonotic infectious diseases; thus, routine sampling and testing of slaughtered animals and abattoir workers are needed for surveillance and control of zoonotic diseases.

\section{Background}

Brucellosis and bovine tuberculosis (bTB) are widespread bacterial diseases of a wide range of mammals, including humans especially those coming in close contact with animals or animal products $(1,2)$. The human brucellosis cases were estimated to be 830,000 worldwide in 2010 and $47.0 \%$ of these were foodborne cases (3), while the World Health Organization estimated 147, 000 cases of bTB (half of which occur in Africa) with 12,500 deaths in humans (4). Both diseases are neglected and endemic in sub-Saharan African countries, including Rwanda where they cause disease burden (5-7) and significant financial losses $(8,9)$. 
Zoonotic tuberculosis is mainly caused by Mycobacterium bovis (10), and occasionally by M. caprae (11, 12), which belong to the Mycobacterium tuberculosis complex (MTBC) (13). About $10.0 \%-15.0 \%$ of human TB cases due to $M$. bovis occur in developing countries where the test-and-slaughter control method is too expensive and therefore not practiced $(10,14)$. Furthermore, in developing countries, zoonotic tuberculosis may be underestimated due to the lack of distinction between M. bovis and $M$. tuberculosis during diagnosis $(15,16)$.

Zoonotic brucellosis is mainly caused by Brucella melitensis (17), B. abortus (18), B. suis (19), and rarely $B$. canis (20). Brucellosis is an occupational disease affecting owners and keepers of animals, laboratory technicians, butchers, veterinarians, and abattoir workers $(21,22)$. Animals are the reservoirs of brucellosis for humans, who contract the disease either directly by inoculation of the pathogen from infective animal tissues through cuts or the skin abrasions, by ingestion of contaminated animal products (raw milk, and milk products), and inhalation of contaminated aerosols $(23,24)$. The clinical signs of human brucellosis, mimic those of acute febrile illnesses such as malaria, typhoid, and rheumatic fever, and this can lead to misdiagnosis or underdiagnosis of brucellosis cases (25). bTB is also an occupational disease affecting similar categories as brucellosis and is transmitted to humans through inhalation of infective particles from diseased cattle or through the ingestion of contaminated animal products such as unpasteurized milk and undercooked meat $(10,26)$. M. bovis - infected humans can transmit the pathogen to other humans through an aerogenous route (27). However, human-tohuman transmission is rare and is only limited to certain circumstances.

For this study, 'other zoonotic diseases' refer to leptospirosis, Q-fever, and cysticercosis. Leptospirosis and Q-fever are acute febrile diseases of both humans and animals and are caused by Leptospira spp. and Coxiella burnetii, respectively $(28,29)$. The diseases are transmitted to humans mainly through contact with infectious tissues and ingestion of contaminated food and water $(28,30)$. To the best of our knowledge, these diseases have not yet been reported in Rwanda. Cysticercosis in cattle is a parasitic disease caused by Cysticercus bovis evolving from an immature form of Taenia saginata, which is a human cestode (31). Humans get infections by eating raw or undercooked beef (32).

In Rwanda, the seroprevalence of brucellosis ranges from $7.4-18.7 \%$ in cattle $(33,34)$ and $6.1-25.0 \%$ in humans $(5,7)$; the prevalence of bTB was $0.5 \%$ in slaughtered cattle (8); while the prevalence of $T$. saginata cysticerci, was $3.0 \%$ in slaughtered cattle (35) and that of $T$. solium was $21.8 \%$ in people with epilepsy (neurocysticercosis) in Rwanda (36). However, no information is available about abattoir workers, who are usually at high risk of exposure to zoonotic diseases $(22,37)$. In this study, 'abattoirrelated' diseases are defined as any animal diseases that are transmissible to humans and thus these diseases that may be contracted at the abattoirs. These included febrile like illnesses (brucellosis, leptospirosis, and Q-Fever), tuberculosis, cysticercosis, and etc.The objective of this study was, therefore, to investigate the awareness of zoonotic brucellosis transmission, zoonotic tuberculosis transmission, leptospirosis, Q-fever, and cysticercosis as well as assess occupational hazards regarding these infections among abattoir workers in Rwanda. The data from this study can be used by the competent 
authorities to raise the awareness level and attend to the preventive needs of abattoir workers and other animal handlers.

\section{Results}

\section{Demographic information}

Out of 180 abattoir workers, $65.6 \%$ (118/180) agreed to participate in this study. Of these 118 participants, $84.7 \%$ (100/118) were employed at high throughput, while $15.3 \%(18 / 118)$ were employed at low throughput abattoirs. Among the respondents, $89.0 \%$ (105/118) were males, while $11.0 \%(13 / 118)$ were females. Most respondents $(56.8 \%, 67 / 118)$ were of the age category 18 - 30 years, followed by those $31-61$ years old $(40.7 \%, 48 / 118)$, and the least were above 60 years of age $(2.5 \%, 3 / 118)$ (Table 1$)$. The proportion of respondents according to their level of education was as follows: primary education $67.8 \%(80 / 118)$, secondary education $18.6 \%(22 / 118)$, and no formal education $13.6 \%(16 / 118)$. Respondents that were married accounted for $61.9 \%$ (73/118), followed by singles $36.4 \%(43 / 118)$, and divorced $1.7 \%$ (2/118). Most respondents were butchermen $(52.6 \%, 61 / 118)$, followed by the group of "others" (comprising of cleaners, permanent sellers of viscera, and animal keepers) at $18.6 \%(22 / 118)$, transporters of carcasses $15.5 \%$ (18/118), and inspectors $14.7 \%$ (17/118). The respondents with work experience of three years and above were $67.8 \%(80 / 118)$, followed by those with one year experience $24.6 \%(29 / 118)$, and the least were those with two years $(7.6 \%, 9 / 118)$. Respondents that worked on cattle were $79.7 \%(94 / 118)$, while $13.6 \%$ (16/118) worked on goats, and $6.8 \%(8 / 118)$ worked on both cattle and goats (Table 1 ). 
Table 1

Sociodemographic information of abattoir workers participating in the study in Rwanda

\begin{tabular}{|c|c|c|c|}
\hline Variables & Interviewed & Frequency n (\%) & $95 \% \mathrm{Cl}$ \\
\hline \multicolumn{4}{|l|}{ Gender } \\
\hline Male & \multirow[t]{2}{*}{118} & $105(89.0)$ & [81.9 - 94.0] \\
\hline Female & & $13(11.2)$ & {$[6.0-18.1]$} \\
\hline \multicolumn{4}{|l|}{ Age category } \\
\hline Young (18-30) & \multirow[t]{3}{*}{118} & $67(56.8)$ & {$[47.3-65.9]$} \\
\hline Medium age (31-60) & & $48(40.7)$ & {$[31.7-50.1]$} \\
\hline Old $\geq 61$ & & $3(2.5)$ & {$[0.5-7.3]$} \\
\hline \multicolumn{4}{|c|}{ Level of your education } \\
\hline No education & \multirow[t]{3}{*}{118} & $16(13.6)$ & {$[8.0-21.1]$} \\
\hline Primary & & $80(67.8)$ & {$[58.6-76.1]$} \\
\hline Secondary & & $22(18.6)$ & [12.1 - 26.9] \\
\hline \multicolumn{4}{|l|}{ Marital status } \\
\hline Married & \multirow[t]{3}{*}{118} & $73(61.9)$ & {$[52.5-70.7]$} \\
\hline Single & & $43(36.4)$ & {$[27.8-45.8]$} \\
\hline Divorced & & $2(1.7)$ & {$[0.2-6.0]$} \\
\hline \multicolumn{4}{|l|}{ Occupation at work } \\
\hline Butcher & \multirow[t]{4}{*}{118} & $61(52.6)$ & [43.1 - 61.9] \\
\hline Inspector & & $17(14.7)$ & {$[8.8-22.4]$} \\
\hline Transporter & & $18(15.5)$ & [9.5 - 23.4] \\
\hline Others & & $22(18.6)$ & {$[12.1-26.9]$} \\
\hline \multicolumn{4}{|c|}{ Duration at working (abattoirs) } \\
\hline 1 year & \multirow[t]{3}{*}{118} & $29(24.6)$ & {$[17.1-33.4]$} \\
\hline 2 years & & $9(7.6)$ & {$[3.6-14.0]$} \\
\hline$\geq 3$ years & & $80(67.8)$ & {$[58.6-76.1]$} \\
\hline \multicolumn{4}{|c|}{ Working on animal species } \\
\hline Cattle & 118 & $94(79.7)$ & [71.3 - 86.5] \\
\hline
\end{tabular}




\begin{tabular}{|llll|}
\hline Variables & Interviewed & Frequency $\mathbf{n}(\%)$ & $\mathbf{9 5 \%} \mathbf{C l}$ \\
\hline Goats & & $16(13.6)$ & {$[8.0-21.1]$} \\
\cline { 3 - 4 } Cattle \& goats & $8(6.8)$ & {$[3.0-12.9]$} \\
\hline
\end{tabular}

$\mathrm{Cl}$, confidence interval; $\mathrm{n}$, number. Abattoir workers in six abattoirs were interviewed about potential risk factors for brucellosis and human tuberculosis, using a semi-structured questionnaire

\section{Awareness of the transmission of zoonotic brucellosis, tuberculosis, and other zoonotic diseases, and the history of diseases among abattoir workers}

This study found a high frequency of awareness of zoonotic tuberculosis transmission $82.2 \%(97 / 118)$, low awareness of zoonotic brucellosis transmission $27.1 \%$ (32/118), and a low frequency of awareness for 'other zoonotic diseases', namely cysticercosis $12.7 \%$ (15/118), leptospirosis 10.2\% (12/118), and Qfever $8.5 \%$ (42/118). Of the 118 respondents, 80 (67.8\%) confirmed that they had been sick three years before the survey and among them, $48.3 \%$ (57/118) suffered from malaria, while other respondents could not remember the name of the disease and reported symptoms. Symptoms of flu and headache were each recorded in $5.1 \%(6 / 118)$ of the respondents. The history of symptoms such as abortion $(0.9 \%)$ $(1 / 118)$ and orchitis $(0.9 \%)(1 / 118)$ was also recorded. Of the 118 respondents, $18(15.3 \%)$ reported that they had been negative for malaria but presented symptoms of fever. The malaria-negative patients also presented with fatigue $11.0 \%$ (13/118), and flu 4.2\% (5/118). Respondents that contracted 'abattoirrelated' diseases three years before the survey $7.6 \%$ (9/118) suffered from typhoid $1.7 \%(2 / 118)$ and presented symptoms of diarrhea $5.9 \%(7 / 118)$ (Additional file 1 )

The univariate analysis showed that the awareness for zoonotic brucellosis transmission was significantly higher among workers from low throughput abattoirs $(50.0 \%, 9 / 18)(p=0.04)$ compared to those from high throughput abattoirs $(23.0 \%, 23 / 100)$. However, the awareness of zoonotic tuberculosis transmission $(85.0 \%, 85 / 100)$, leptospirosis $(12.0 \%, 12 / 100)$, cysticercosis $(13.0 \%, 13 / 100)$, and Q-fever $(9.0 \%, 9 / 100)$ was higher in workers from high throughput abattoirs compared to those from low throughput abattoirs but this was not statistically significant (Table 2). 
Table 2

Awareness of transmission of zoonotic brucellosis, zoonotic tuberculosis, and other zoonotic diseases stratified by the capacity of abattoirs in Rwanda

\begin{tabular}{|c|c|c|c|c|c|}
\hline Variables (awareness) & Categories & $\begin{array}{l}\text { High } \\
\text { throughput }\end{array}$ & $\begin{array}{l}\text { Low } \\
\text { throughput }\end{array}$ & $\begin{array}{l}\text { Odds } \\
\text { Ratios }\end{array}$ & $\begin{array}{l}\mathrm{P} \text { - } \\
\text { value }\end{array}$ \\
\hline \multirow[t]{2}{*}{ zoonotic transmission for TB } & No & $\begin{array}{l}15.0 \% \\
(15 / 100)\end{array}$ & $\begin{array}{l}33.3 \% \\
(6 / 18)\end{array}$ & \multirow[t]{2}{*}{$\begin{array}{l}{[0.12-} \\
1.17]\end{array}$} & \multirow[t]{2}{*}{0.12} \\
\hline & Yes & $\begin{array}{l}85.0 \% \\
(85 / 100)\end{array}$ & $\begin{array}{l}66.7 \% \\
(12 / 18)\end{array}$ & & \\
\hline \multirow[t]{2}{*}{$\begin{array}{l}\text { zoonotic transmission for } \\
\text { brucellosis }\end{array}$} & No & $\begin{array}{l}77.0 \% \\
(77 / 100)\end{array}$ & $\begin{array}{l}50.0 \% \\
(9 / 18)\end{array}$ & \multirow[t]{2}{*}{$\begin{array}{l}{[1.19} \\
-9.42]\end{array}$} & \multirow[t]{2}{*}{0.04} \\
\hline & Yes & $\begin{array}{l}23.0 \% \\
(23 / 100)\end{array}$ & $\begin{array}{l}50.0 \% \\
(9 / 18)\end{array}$ & & \\
\hline \multirow[t]{2}{*}{ Leptospirosis } & No & $\begin{array}{l}88.0 \% \\
(88 / 100)\end{array}$ & $\begin{array}{l}100.0 \% \\
(18 / 18)\end{array}$ & \multirow[t]{2}{*}{$\begin{array}{l}{[0.00} \\
-1.96]\end{array}$} & \multirow[t]{2}{*}{0.2} \\
\hline & Yes & $\begin{array}{l}12.0 \% \\
(12 / 100)\end{array}$ & $0.0 \%(0 / 18)$ & & \\
\hline \multirow[t]{2}{*}{ Cysticercosis } & No & $\begin{array}{l}87.0 \% \\
(87 / 100)\end{array}$ & $\begin{array}{l}88.9 \% \\
(16 / 18)\end{array}$ & \multirow[t]{2}{*}{$\begin{array}{l}{[0.08-} \\
4.29]\end{array}$} & \multirow[t]{2}{*}{1} \\
\hline & Yes & $\begin{array}{l}13.0 \% \\
(13 / 100)\end{array}$ & $\begin{array}{l}11.1 \% \\
(2 / 18)\end{array}$ & & \\
\hline \multirow[t]{2}{*}{ Q-Fever } & No & $\begin{array}{l}91.0 \% \\
(91 / 100)\end{array}$ & $\begin{array}{l}94.4 \% \\
(17 / 18)\end{array}$ & \multirow[t]{2}{*}{$\begin{array}{l}{[0.01-} \\
4.8]\end{array}$} & \multirow[t]{2}{*}{1} \\
\hline & Yes & $9.0 \%(9 / 100)$ & $5.6 \%(1 / 18)$ & & \\
\hline
\end{tabular}

TB: tuberculosis

\section{Behavior And Practices Predisposing Abattoir Workers To Zoonotic Diseases}

Consuming raw meat and uninspected meat at least once was each recorded in $0.9 \%(1 / 118)$ of the respondents, while none of the respondents consumed condemned meat. Most respondents $(70.3 \%$, 83/118) had cut their hands at some point while working in the abattoir and among them, $39.8 \%$ $(47 / 118)$ have been working with hand injuries, while only $7.6 \%(9 / 118)$ worked after treatment. Having got splashed (with animal fluid/blood) on the face was recorded in $74.6 \%(88 / 118)$ of respondents. Most of the respondents $95.8 \%(113 / 118)$ washed their hands and of these, $70.8 \%(80 / 118)$ washed their hands every time after touching potential contaminants, while the remaining $25.0 \%$ washed their hands once or twice daily. None of the 118 respondents wore a facemask or goggles, and only $9.3 \%(11 / 118)$ wore gloves, and of these, only $6.8 \%(8 / 118)$ used them regularly. Wearing overhead covers was recorded in $1.7 \%(2 / 118)$ of respondents. Most of the respondents $94.1 \%(111 / 118)$ wore overalls for preventive 
clothing, but only $43.2 \%(48 / 118)$ always wore their overalls. Four respondents (3.4\%) did not wear gumboots and among the $96.6 \%$ who wore gumboots, $11.4 \%$ (13/118) wore them occasionally. Twentyeight percent $[28.0 \%(33 / 118)]$ of the respondents had their breakfast while wearing their overalls (Additional file 2).

\section{Pairwise Associations Between Exposure And Outcome Variables}

The occupation was significantly associated with contracting illness three years before the study, awareness of zoonotic tuberculosis transmission, and awareness of zoonotic brucellosis transmission. Splitters \& transporters of carcasses $(77.8 \%, 14 / 18)$ were more likely to have been sick three years before the study $(p=0.003)$ and $22.2 \%(4 / 18)$ of them became negative to malaria while manifesting fever and headache $(p=0.72)$. Butchers $(11.5 \%, 7 / 118)$ were more likely to contract 'abattoir-related'diseases compared to other workers, but this was not significant $(p=0.52)$. All meat inspectors $(100 \%, 17 / 17)$ were more aware of the zoonotic tuberculosis transmission than other abattoir workers $(p=0.05)$, and a large proportion of these $(76.5 \%, 13 / 17)$ was aware of zoonotic brucellosis transmission $(p<0.001)$ compared to other workers.

The levels of education were significantly associated with contracting illness, and workers with primary education $(75.0 \%, 60 / 80)$ were more prone to sickness than other workers with no education level $(p=$ $0.003)$. Although not significant, workers with primary education $(10.0 \%, 8 / 80)$ had contracted 'abattoirrelated' diseases, while $(17.5 \%, 14 / 80)$ had been negative to malaria yet they presented fever as a symptom. Workers with secondary education were more aware of zoonotic tuberculosis transmission ( $p<$ $0.001)$, and zoonotic brucellosis transmission than illiterates and workers with primary education ( $\mathrm{p}<$ $0.001)$.

Workers with three years' work experience and above $(10 \%, 8 / 80)$ were significantly associated with being sick $(77.5 \%, 62 / 80)$ compared to the one or two years-work experience categories $(p=0.0006)$, and also contracted 'abattoir-related' diseases $(10.0 \%, 8 / 80)$ more than other workers $(p=0.61)$. More workers with two years-work experience were negative to malaria $(22.2 \%, 2 / 9)(p=0.01)$ and were more aware of the zoonotic brucellosis transmission $(6 / 9,66.7 \%)(p=0.004)$ than those of 1 year or $\geq 3$ years-working experience. Most respondents (82.0\%) irrespective of their duration at work were aware of zoonotic tuberculosis transmission, while the frequency of awareness of zoonotic brucellosis transmission was generally lower $(21.1 \%, 32 / 118)$. A high proportion of abattoir workers with accidental cuts on their hands experienced sickness $(71.1 \%, 59 / 83)(p=0.12)$, contracted 'abattoir-related' diseases $(10.9 \%, 9 / 83)(p=$ $0.05)$, were negative to malaria $(20.5 \%, 17 / 83)(p=0.013)$, were aware of zoonotic tuberculosis transmission $(85.5 \%, 71 / 83)(p=0.23)$, and zoonotic brucellosis transmission $(30.1 \%, 25 / 83)(p=0.36)$ (Table 3). 
Table 3

Pairwise associations between exposure and outcome variables among abattoir workers in Rwanda

\begin{tabular}{|c|c|c|c|c|c|c|}
\hline $\begin{array}{l}\text { Exposure } \\
\text { variables }\end{array}$ & Categories & $\begin{array}{l}\text { Being } \\
\text { sick in } \\
\text { the the } 3 \\
\text { years }\end{array}$ & $\begin{array}{l}\text { Contracting } \\
\text { 'abattoir- } \\
\text { related' } \\
\text { diseases }\end{array}$ & $\begin{array}{l}\text { negative } \\
\text { to } \\
\text { malaria }\end{array}$ & $\begin{array}{l}\text { Awareness } \\
\text { zoonotic } \\
\text { tuberculosis }\end{array}$ & $\begin{array}{l}\text { Awareness } \\
\text { zoonotic } \\
\text { brucellosis }\end{array}$ \\
\hline \multirow[t]{4}{*}{ Occupation } & Butchers & $\begin{array}{l}46 / 61 \\
(75.4 \%)\end{array}$ & $7 / 61(11.5 \%)$ & $\begin{array}{l}10 / 61 \\
(16.4 \%)\end{array}$ & $\begin{array}{l}51 / 61 \\
(83.6 \%)\end{array}$ & $\begin{array}{l}11 / 61 \\
(18.0 \%)\end{array}$ \\
\hline & Inspectors & $\begin{array}{l}5 / 17 \\
(29.4 \%)\end{array}$ & $1 / 17(5.9 \%)$ & $\begin{array}{l}2 / 17 \\
(11.8 \%)\end{array}$ & $\begin{array}{l}17 / 17 \\
(100.0 \%)\end{array}$ & $\begin{array}{l}13 / 17 \\
(76.5 \%)\end{array}$ \\
\hline & Transporters & $\begin{array}{l}14 / 18 \\
(77.8 \%)\end{array}$ & $0 / 18(0.0 \%)$ & $\begin{array}{l}4 / 18 \\
(22.2 \%)\end{array}$ & $\begin{array}{l}14 / 18 \\
(77.8 \%)\end{array}$ & $5 / 18(27.8 \%)$ \\
\hline & Others & $\begin{array}{l}13 / 22 \\
(59.1 \%)\end{array}$ & $1 / 22(4.5 \%)$ & $\begin{array}{l}2 / 22 \\
(9.1 \%)\end{array}$ & $\begin{array}{l}15 / 22 \\
(68.2 \%)\end{array}$ & $3 / 22(13.6 \%)$ \\
\hline$P$ value & & 0.003 & 0.520 & 0.720 & 0.050 & 0.000 \\
\hline \multirow[t]{3}{*}{ Education } & None & $\begin{array}{l}10 / 16 \\
(62.5 \%)\end{array}$ & $1 / 16(6.3 \%)$ & $\begin{array}{l}2 / 16 \\
(12.5 \%)\end{array}$ & $\begin{array}{l}6 / 16 \\
(37.5 \%)\end{array}$ & $1 / 16(6.3 \%)$ \\
\hline & Primary & $\begin{array}{l}60 / 80 \\
(75.0 \%)\end{array}$ & $8 / 80(10.0 \%)$ & $\begin{array}{l}14 / 80 \\
(17.5 \%)\end{array}$ & $\begin{array}{l}71 / 80 \\
(88.8 \%)\end{array}$ & $9 / 80(11.3 \%)$ \\
\hline & Secondary & $\begin{array}{l}8 / 22 \\
(36.4 \%)\end{array}$ & $0 / 22(0.0 \%)$ & $\begin{array}{l}2 / 22 \\
(9.1 \%)\end{array}$ & $\begin{array}{l}20 / 22 \\
(90.9 \%)\end{array}$ & $\begin{array}{l}22 / 22 \\
(100.0 \%)\end{array}$ \\
\hline$P$ value & & 0.003 & 0.370 & 0.740 & 0.000 & 0.000 \\
\hline \multirow[t]{3}{*}{$\begin{array}{l}\text { Duration at } \\
\text { work }\end{array}$} & 1 year & $\begin{array}{l}12 / 29 \\
(41.4 \%)\end{array}$ & $1 / 29(3.5 \%)$ & $\begin{array}{l}0 / 29 \\
(0.0 \%)\end{array}$ & $\begin{array}{l}26 / 29 \\
(89.7 \%)\end{array}$ & $11 / 19(37.9 \%)$ \\
\hline & 2 years & $\begin{array}{l}4 / 9 \\
(44.4 \%)\end{array}$ & $0 / 9(0.0 \%)$ & $\begin{array}{l}2 / 9 \\
(22.2 \%)\end{array}$ & $8 / 9(88.9 \%)$ & 6/9 (66.7\%) \\
\hline & $\geq 3$ years & $\begin{array}{l}62 / 80 \\
(77.5 \%)\end{array}$ & $8 / 80(10 \%)$ & $\begin{array}{l}16 / 80 \\
(20.0 \%)\end{array}$ & $\begin{array}{l}63 / 80 \\
(82.2 \%)\end{array}$ & $15 / 80(18.8 \%)$ \\
\hline$P$ value & & 0.0006 & 0.6100 & 0.0100 & 0.4900 & 0.0040 \\
\hline \multirow[t]{2}{*}{$\begin{array}{l}\text { Cutting } \\
\text { hand }\end{array}$} & No & $\begin{array}{l}19 / 35 \\
(54.3 \%)\end{array}$ & 0/35 (0.0\%) & $\begin{array}{l}1 / 35 \\
(2.9 \%)\end{array}$ & $\begin{array}{l}26 / 35 \\
(74.3 \%)\end{array}$ & $7 / 35$ (20.0\%) \\
\hline & Yes & $\begin{array}{l}59 / 83 \\
(71.1)\end{array}$ & 9/83 (10.9\%) & $\begin{array}{l}17 / 83 \\
(20.5 \%)\end{array}$ & $\begin{array}{l}71 / 83 \\
(85.5 \%)\end{array}$ & $\begin{array}{l}25 / 83 \\
(30.1 \%)\end{array}$ \\
\hline$P$ value & & 0.120 & 0.050 & 0.013 & 0.230 & 0.360 \\
\hline
\end{tabular}


Significant variables from the pairwise associations were assessed further using correspondence analysis. The two correspondence dimensions, 1 and 2, explain a high percentage (96.4\%) of the variance, implying that the variable mapping represents most of the information from the collected data (Figure 1). The different levels of education showed varying degrees of association with the awareness of zoonotic brucellosis transmission, with the highest association recorded for secondary education, and a negative association amongst workers with primary education or the illiterate. Workers with secondary education were highly associated with awareness about zoonotic tuberculosis transmission, while negative associations were observed for primary or no education (Figure 1). Meat inspectors were highly associated with awareness about zoonotic brucellosis transmission, but at the same time more likely to cut their hands, compared to transporters of carcasses, butchers, and other worker categories (Figure 1). Respondents who had been sick within the three years before the survey most likely had three or more years-experience (compared to one year or two years), and those with primary education (compared to secondary education or illiterates).

\section{Discussion}

Brucellosis and bTB are zoonotic diseases that are endemic in Rwanda. This study aimed to investigate, for the first time in Rwanda, the awareness of the transmission of zoonotic diseases (brucellosis, bTB, cysticercosis, leptospirosis, and Q-fever), the history of diseases among 118 abattoir workers during the three years before this survey, occupational hazards associated with daily practices and behaviors of workers, and to assess the association between exposure and outcome variables. This study found that abattoir workers $(82.2 \%)$ were more aware of the transmission of zoonotic tuberculosis than brucellosis (27.1\%). Few workers have heard of cysticercosis (12.7\%), leptospirosis (10.2\%), and Q-fever (8.5\%) weather in animals or humans. Practices and behaviors predisposing abattoir workers to zoonotic diseases were recorded in this study. There was a significant association between the awareness of zoonotic diseases (TB and brucellosis) and the occupation ( $p=0.05$ and $p<0.001$ ), as well as the level of education $(p<0.001)$ of abattoir workers.

The level of awareness was higher for the transmission of zoonotic TB than brucellosis and other diseases. The high awareness for zoonotic tuberculosis transmission may be due to the regular occurrence of tuberculous lesions in slaughtered cattle resulting in the condemnation of the carcasses (one case occurred during this study), and abattoir workers being aware of colleagues, friends, and relatives with tuberculosis infection as mentioned by respondents during this study. Moreover, abattoir workers are required to present an annual certificate of medical examination which could have raised awareness of tuberculosis. Moreover, one cleaner had recovered from tuberculosis in the past and during this study, two abattoir workers were diagnosed with TB and placed into isolation but we could not trace the origin of the infection for all these cases due to the inability of laboratory tests to distinguish MTBC species $(14,16)$. Furthermore, extra-pulmonary human cases due to M. bovis $(38,39)$ may be missed because lymph nodes biopsies are rarely collected for the diagnosis of human TB. Instead, sputum is the specimen of choice to be tested (39). The level of awareness for zoonotic tuberculosis transmission 
found in this study was consistent with $93.3 \%$ that was reported in central Ethiopia among abattoirs workers (40). Therefore, the awareness of zoonotic TB may be commonly high among abattoir workers.

The low awareness for zoonotic brucellosis transmission was consistent with a recent study on brucellosis in women presenting with abortions in Nyagatare district hospital, Rwanda (5). This low awareness may be attributable to the lack of routine diagnosis and treatment of human brucellosis in hospitals and health centers in Rwanda. Human brucellosis may therefore be misdiagnosed for other acute febrile diseases namely typhoid fever and malaria (25). Moreover, the level of awareness for zoonotic brucellosis transmission $(27.1 \%$ ) obtained in this study was lower than that $(44.2 \%)$ reported in Ethiopia (41) and (76\%) Tanzania (42) among abattoir workers. These differences may be due to the lower level of education of abattoir employees in Rwanda. The seroprevalence of brucellosis ranges from $6.1-25.0 \%$ in women presenting abortions in Rwanda $(5,7)$. Therefore, the low awareness observed in the present abattoir study may simply imply that the brucellosis prevalence may be higher in occupational groups who come frequently in contact with animals. There is thus a need for interdisciplinary collaboration, raising the awareness and knowledge of human health professionals and including human brucellosis among the routinely diagnosed and treated diseases in Rwanda.

The low awareness for cysticercosis (12.7\%) and leptospirosis (10.2\%) recorded in this study was lower than the $89.0 \%$ and $33.0 \%$ recorded in Kenya for cysticercosis and leptospirosis, respectively (43). This indicates that abattoir workers from Rwanda were probably less trained on these diseases compared to their neighbors thereby the need to enhance education in Rwanda. Furthermore, a 3.0\% prevalence of bovine cysticercosis was reported at Nyagatare district slaughterhouse, Rwanda (35), and a high prevalence of $21.8 \%$ of cysticercosis was reported in people with epilepsy in the Southern Province of Rwanda (36). These findings show that leptospirosis, Q-fever, and cysticercosis may be endemic in Rwandan cattle and thus constitute a risk of infection for workers in abattoirs with poor hygienic and biosafety measures.

The majority $(67.8 \%)$ of abattoir workers reported that they had been sick within the three years before the survey and $7.6 \%$ confirmed contracting diseases from the abattoirs. Apart from malaria that was reported by $48.3 \%$ of workers, other workers could not remember names of diseases diagnosed in the last three years, instead, they reported the symptoms. Diarrhea was a symptom of unknown origin which was reported by seven participants $(28.0 \%)$ of which five reported eating while working. This was not surprising since cases of diarrhea are commonly reported among abattoir workers (44-47). Other symptoms that were reported included fatigue $(11.0 \%)$ and flu $(9.3 \%)$ that were reported by malarianegative patients, and fever $(15.3 \%)$, headache $(5.1 \%)$, abortion $(0.9 \%)$, orchitis $(0.9 \%)$, as well as nephritis-related symptoms (3.4\%) of unknown origin. However, these symptoms are commonly observed in humans with diseases like brucellosis (48), leptospirosis (49), and Q-fever (50) as earlier reported among abattoir workers $(22,51)$. Alghought, these diseases have never been reported in abattoir workers in Rwanda, brucellosis seroprevalence has been reported in $10.0 \%$ of workers in neighboring Uganda (52), and $19.5 \%$ in Tanzania (22), and odds of contracting brucellosis were higher among abattoir workers compare to other occupational groups in Uganda (53). The nephritis-related symptoms may also be 
caused by $M$. bovis which has been isolated in the urogenital tract of humans (54). Abattoir workers being regularly exposed to carcasses, blood, urine, and hides from infectious animals are at high risk of contracting these diseases. There is therefore a need to investigate and control various diseases in animals to protect abattoir workers and consumers. It is also necessary to educate workers on zoonotic diseases and hygienic practices and provide them with appropriate personal protective equipment (PPE).

Practices and behaviors predisposing abattoir workers to zoonotic diseases were recorded in this study. Most $(70.3 \%)$ of workers cut their hands while only meat inspectors wore gloves $(9.3 \%)$, and $39.8 \%$ of employees worked with bare and injured hands. The frequency of hand-cut injuries in this study was higher than the $47.0 \%$ reported in Nigeria (55), and the proportion of wearing gloves was lower than $18.6 \%$ reported in Ethiopia (41). This is of concern since working with bare and injured hands had been associated with the risk of contracting brucellosis in Nigeria (21). Moreover, certain workers of this study (28.0\%) had their breakfast while working, and this proportion of workers was higher than $14.4 \%$ reported in Nigeria (55). In this study, the majority $(74.6 \%)$ of workers experienced splashes of fluid or blood onto their faces (eyes, nostrils, and mouth) while none wore facemasks and goggles. This is worrying because a study in Tanzania demonstrated that abattoir workers that did not adhere to the hygiene and use of protective gears were three times more at risk of contracting brucellosis (52). The practices of working with bare and injured hands, and eating while working, as recorded in this study confirm the low awareness and poor epidemiological knowledge of pathogens causing zoonotic diseases. There is therefore a need for the concerned veterinary public health authorities to strengthen the implementation of rules and regulations regarding the biosafety in abattoirs and raise awareness of the abattoir workers and other stakeholders, through educational campaigns.

Univariate and correspondence analyses showed that there was a significant association between the awareness for zoonotic TB and brucellosis and the occupation ( $p=0.05, p<0.001)$, as well as the level of education $(p<0.001)$. This was in agreement with studies in Nigeria (21), Tanzania (42), and Ethiopia (41). In this present study, meat inspectors and workers with secondary education were more likely to be aware of zoonotic tuberculosis and brucellosis than other occupational and educational group categories. Moreover, our findings showed that $54.5 \%$ of workers with secondary education were meat inspectors, and most of them had a veterinary education background while others had gained knowledge and skills through work experience which can explain the higher level of awareness. Therefore, education should raise the awareness among other workers.

Both univariate and correspondence analyses showed that being sick within the three years before the study was significantly associated with an occupation $(p=0.003)$, the level of education $(p=0.003)$, and the duration at work $(p<0.001)$. Transporters of carcasses and butchers, workers with primary education, and workers with experience of three years and above were more likely to become sick than other group categories. This is in agreement with the findings in Nigeria in which illiterate and workers with primary education were more likely to become seropositive to brucellosis $(21,41)$. Generally, workers with lower levels of education are assigned to cleaning and washing viscera, jobs in which workers lack the understanding of the high burden of harmful microorganisms they are exposed to. Abattoirs workers with 
more than five years at work were more likely to be seropositive to Brucella spp. in Nigeria (21), while those with more than 40 years at work were more likely to be positive to M. bovis (56). This affirms the association between age and illnesses, in that, workers with advanced age and weakened immune systems may have been exposed to the pathogens for a long period, leading to a greater risk of contracting infections. Slaughtered cattle are the sentinels of zoonotic and other animal diseases. Thus, if meat inspection findings can be confirmed by laboratory evidence, this would play a significant role in the surveillance and control of infectious diseases.

\section{Conclusions}

This study demonstrated a low awareness of transmission for zoonotic brucellosis, leptospirosis, Q-fever, and cysticercosis among abattoir workers. Noncompliance with biosafety protection was associated with the lack of epidemiological knowledge on the transmission routes of zoonotic diseases. It is necessary to raise awareness through education campaigns and facilitate the workers with appropriate personal protective equipment (PPE). Our study has therefore generated information for the concerned authorities to enforce appropriate practices and disease control in the cattle population. The coordination and collaboration between abattoirs, veterinary, and public health authorities are important for the surveillance and control of zoonotic diseases. There is therefore a need to further monitor zoonotic diseases among abattoir workers.

\section{Materials And Methods}

\section{Study Area}

This study was based on conducted with 100 workers in four high throughput and 18 workers in two low throughput abattoirs. The six abattoirs are located in six of the 30 districts of Rwanda. In all the selected premises, cattle were the main slaughtered animals. The cattle population in Rwanda was estimated to be 1,293,768 in 2018 (57) and the current human population is 12,952,218 (58). There are 12 modern abattoirs in the whole country and at least one traditional slaughterhouse in each of the 30 districts of Rwanda. Of the modern abattoirs, 11 slaughter domestic ruminants (goats and cattle), while one slaughter only pigs. The selected abattoirs are shown in Figure 2.

\section{Study Design And Sample Size Determination}

\section{The study was a cross-sectional study design, carried out from August 2018 through September 2019 to assess the awareness of brucellosis, tuberculosis, and other zoonotic diseases among abattoir workers, and to determine the}


knowledge, attitudes, and practices that could be associated with the risks of acquiring zoonotic diseases among the workers. Abattoirs that consented to participate in this study were purposively selected. The selected abattoirs were classified as high throughput if they slaughtered more than 50 animals per day and low throughput for those that slaughtered 10 to 30 animals per day. Three of the six abattoirs slaughtered cattle and goats in the same $(n=2)$ and separate $(n=1)$ building, while the other three slaughtered only cattle. The sample size of the interviewed abattoir workers was determined using the formula previously described (59):

$$
\text { Samplesize }=\frac{Z^{2} P(1-P)}{d^{2}}
$$

Where $p$ is an expected prevalence of $10 \%$ based on a previous brucellosis study in cattle in Rwanda (60). A 95\% confidence level $(z)$ and a precision of $5 \%(d)$ were considered. The calculated sample size was 138 abattoir workers but only 118 consented to participate in the study and these were immediately enrolled. Other people who were not abattoir employees but held permanent jobs in the abattoirs were also included in the study. These included sellers of viscera and cattle keepers.

Participant'S Enrolment And Data Collection

All abattoir workers (from 18 years and above) of both genders and who have worked in the abattoir for at least one year, were listed in the sampling frame. The purpose of the study and implications of participating were explained to the abattoir workers. Participants were allowed to ask questions and to voluntarily agree to participate in the study by signing the consent form. Workers who needed further 
assistance to understand the consent form were given chance to get appropriate interpretation by their trusted colleagues. The questionnaire was pre-tested with five abattoir workers who were not included in the final interviews, and the questionnaire was adjusted accordingly. Data were collected during face-toface interviews using the questionnaire. The interviews were administered in the participants' language "Kinyarwanda" by the primary investigator, and diseases were translated into the local language apart from leptospirosis and Q-fever which were explained based on clinical signs. Each interview took about 5 minutes. The collected data included demographic information of the respondents (age, sex, marital status, education level, occupation, and duration at work). Other potential risk factors that were assessed included the awareness of zoonotic brucellosis and zoonotic tuberculosis transmission, and other zoonotic diseases, and attitudes and daily practices at the abattoirs. The major exposure factors assessed were wearing personal protective equipment, hand cuts, washing hands, eye splashes, and eating when working. Thus, the awareness of other zoonotic diseases such as leptospirosis, Q-fever, and cysticercosis was also assessed.

\section{Data analysis}

The data were managed in Microsoft Excel spreadsheets and grouped into two categories. The first category comprised potential exposure variables, including kind of job, education level, duration at work, and cutting hands. The second category comprised likely outcome variables, including illness in the last five years, contracting diseases from abattoirs, becoming negative to malaria while presenting fever, awareness of zoonotic tuberculosis transmission, and zoonotic brucellosis transmission. Descriptive statistics were conducted to determine the proportions of abattoir workers by demographics and by each potential risk factor, as well as likely outcomes from the survey. Univariate analyses were performed to assess pairwise associations between the potential exposure variables and likely outcome variables using the Chi-square test. Subsequently, significant variables from univariate analysis $(p<0.05)$ were included in a correspondence analysis to explore the proximal associations between variables, namely education level, awareness about zoonotic brucellosis or zoonotic TB, years of work, occupation, history of personal illness, and hand-cut, and these relationships were visualized on a two-dimensional axis. Eigenvalues were estimated to determine the amount of variances expressed by each of the correspondence axis and the number of dimensions to retain. An asymmetric plot was generated to determine the distance between the variables. Data analysis was done using Epilnfo software version 7.2.3.1 and the R software version 4.0 (61) at a $5 \%$ level of significance. The coordinates of each slaughtering premises were recorded using a geographic positioning system (GPS) device (Garmin etrex 10, Lexena, KS, USA) and analyzed to produce a map using ArcGIS software version 10.2.

\section{Abbreviations}

bTB

bovine tuberculosis

MTBC

Mycobacterium tuberculosis complex (MTBC)

Page $15 / 23$ 
tuberculosis

$\mathrm{Cl}$

confidence interval

$\mathrm{n}$

number

B

brucellosis

PPE

appropriate personal protective equipment

GPS

a geographic positioning system

\section{Declarations}

\section{Ethics approval and consent to participate}

This study was approved by the research screening and ethical clearance committee of the College of Agriculture, Animal Sciences and Veterinary Medicine, University of Rwanda (Ref: 026/DRIPGS/2017). Ethical clearance was also obtained from the Institutional Review Board of the College of Medicine and Health Sciences, University of Rwanda ( $\left.N^{\circ} 006 / C M H S ~ I R B / 2020\right)$, and the Animal Ethics Committee of the Faculty of Veterinary Science, University of Pretoria, South Africa (V004/2018-2020). Informed verbal consents were obtained from district officials and a consent form was signed by each participant.

\section{Consent for publication}

Not applicable

\section{Availability of data and materials}

The datasets generated and analysed in this study are included in this article and its supplementary information files.

\section{Competing interests}

Authors declare that there are no conflicts of interest. The funders had no role in the design of the study, in the collection, analyses, or interpretation of data, in the writing of the manuscript, or in the decision to publish the results.

\section{Funding}

This research was funded by the Institute of Tropical Medicine Antwerp, Belgium through a grant agreement with the Department of Veterinary Tropical Diseases, University of Pretoria, grant number ITM 
FA4. The funding body did not play a role in the design, analysis, and reporting of the study.

\section{Authors' contributions}

Conceptualization: JBN, FBK, AM, and HvH; methodology: JBN, FBK, AM, and HvH; Formal analysis: $\mathrm{CB}$ and JBN; Investigation and data collection: JBN and RG; Writing-original draft preparation: JBN; writingreview and editing: JBN, FBK, AM, and $\mathrm{HvH}$; Supervision: $\mathrm{HvH}, \mathrm{AM}$, and FBK; Project administration: $\mathrm{HvH}$; Resources and Funding acquisition: $\mathrm{HvH}$. All authors have read and approved the manuscript.

\section{Acknowledgments}

Authors would like to acknowledge the Institute of Tropical Medicine, Belgium, and the Department of Veterinary Tropical Disease, South Africa, for funding the project. Our acknowledgments also go to the University of Rwanda for the facilitation of study. We also thank the managers of abattoirs, Kabahire Louise and other inspectors, and participants for their good cooperation.

\section{References}

1. Corbel MJ. Brucellosis in humans and animals. Corbel MJ, editor2006. ix +89 pp. p.

2. Michel AL, Müller B, van Helden PD. Mycobacterium bovis at the animal-human interface: A problem, or not? Veterinary Microbiology. 2010;140(3):371-81.

3. Kirk MD, Pires SM, Black RE, Caipo M, Crump JA, Devleesschauwer B, et al. World Health Organization Estimates of the Global and Regional Disease Burden of 22 Foodborne Bacterial, Protozoal, and Viral Diseases, 2010: A Data Synthesis. PLOS Medicine. 2015;12(12):e1001921.

4. WHO WHO. Roadmap for zoonotic tuberculosis 2017. Geneva World Health Organization 2017. Report No.: 9241513047.

5. Gafirita J, Kiiza G, Murekatete A, Ndahayo LL, Tuyisenge J, Mashengesho V, et al. Seroprevalence of Brucellosis among Patients Attending a District Hospital in Rwanda. The American Journal of Tropical Medicine and Hygiene. 2017;97(3):831-5.

6. Marcotty T, Matthys F, Godfroid J, Rigouts L, Ameni G, Gey van Pittius N, et al. Zoonotic tuberculosis and brucellosis in Africa: neglected zoonoses or minor public-health issues? The outcomes of a multi-disciplinary workshop. Annals of Tropical Medicine \& Parasitology. 2009;103(5):401-11.

7. Rujeni N, Mbanzamihigo L. Prevalence of brucellosis among women presenting with abortion/stillbirth in Huye, Rwanda. Journal of Tropical Medicine. 2014;2014:740479-Article ID

8. Habarugira G, Rukelibuga J, Nanyingi MO, Mushonga B. Bovine tuberculosis in Rwanda: Prevalence and economic impact evaluation by meat inspection at Société des Abattoirs de NyabugogoNyabugogo Abattoir, Kigali. Journal of the South African Veterinary Association. 2014;85(1).

9. McDermott J, Grace D, Zinsstag J. Economics of brucellosis impact and control in low-income countries. Revue Scientifique Et Technique-Office International Des Epizooties. 2013;32(1):249-61. 
10. Cosivi O, Grange JM, Daborn CJ, Raviglione MC, Fujikura T, Cousins D, et al. Zoonotic tuberculosis due to Mycobacterium bovis in developing countries. Emerging infectious diseases. 1998;4(1):59-70.

11. Cvetnic Z, Katalinic-Jankovic V, Sostaric B, Spicic S, Obrovac M, Marjanovic S, et al. Mycobacterium caprae in cattle and humans in Croatia. The International Journal of Tuberculosis and Lung Disease. 2007;11(6):652-8.

12. Prodinger WM, Indra A, Koksalan OK, Kilicaslan Z, Richter E. Mycobacterium caprae infection in humans. Expert review of anti-infective therapy. 2014;12(12):1501-13.

13. Brosch R, Gordon SV, Marmiesse M, Brodin P, Buchrieser C, Eiglmeier K, et al. A new evolutionary scenario for the Mycobacterium tuberculosis complex. Proceedings of the national academy of Sciences. 2002;99(6):3684-9.

14. de la Rua-Domenech R. Human Mycobacterium bovis infection in the United Kingdom: Incidence, risks, control measures and review of the zoonotic aspects of bovine tuberculosis. 2006. p. 77-109.

15. Cosivi O, Meslin F, Daborn C, Grange J. Epidemiology of Mycobacterium bovis infection in animals and humans, with particular reference to Africa. Revue Scientifique et Technique-Office International des Epizooties. 1995;14(3):733-50.

16. Wedlock DN, Skinner MA, de Lisle GW, Buddle BM. Control of Mycobacterium bovis infections and the risk to human populations. Microbes and infection. 2002;4(4):471-80.

17. Bruce D. Note on the discovery of a microorganism in Malta Fever. [London]: [John Brigg]; 1887.

18. Spink WW, Thompson H. Human brucellosis caused by Brucella abortus, strain 19. Journal of the American Medical Association. 1953;153(13):1162-5.

19. Forbes LB. Isolates of Brucella suis biovar 4 from animals and humans in Canada, 1982-1990. The Canadian Veterinary Journal. 1991;32(11):686.

20. Lucero N, Corazza R, Almuzara M, Reynes E, Escobar G, Boeri E, et al. Human Brucella canis outbreak linked to infection in dogs. Epidemiology \& Infection. 2010;138(2):280-5.

21. Aworh MK, Okolocha E, Kwaga J, Fasina F, Lazarus D, Suleman I, et al. Human brucellosis: seroprevalence and associated exposure factors among abattoir workers in Abuja, Nigeria-2011. The Pan African Medical Journal. 2013;16.

22. Mirambo MM, Mgode GF, Malima ZO, John M, Mngumi EB, Mhamphi GG, et al. Seroposotivity of Brucella spp. and Leptospira spp. antibodies among abattoir workers and meat vendors in the city of Mwanza, Tanzania: a call for one health approach control strategies. PLoS neglected tropical diseases. 2018;12(6):e0006600.

23. Osoro EM, Munyua P, Omulo S, Ogola E, Ade F, Mbatha P, et al. Strong association between human and animal Brucella seropositivity in a linked study in Kenya, 2012-2013. The American journal of tropical medicine and hygiene. 2015;93(2):224-31.

24. Sadler WW. Present evidence on the role of meat in the epidemiology of human brucellosis. American Journal of Public Health and the Nations Health. 1960;50(4):504-14. 
25. Crump JA, Morrissey AB, Nicholson WL, Massung RF, Stoddard RA, Galloway RL, et al. Etiology of severe non-malaria febrile illness in Northern Tanzania: a prospective cohort study. PLoS Negl Trop Dis. 2013;7(7):e2324.

26. Thoen CO, Steele JH, Kaneene JB. Zoonotic tuberculosis: Mycobacterium bovis and other pathogenic mycobacteria: John Wiley \& Sons; 2014.

27. Acha P N SB. Zoonotic tuberculosis. In: Acha P N SB, editor. Zoonoses and communicable diseases common to man and animals. 503. 2nd edition. ed. Washington, DC: Pan American Health Organization/World Health Organization; 1987. p. 181-92.

28. Angelakis E, Raoult D. Q fever. Veterinary microbiology. 2010;140(3-4):297-309.

29. De Vries SG, Visser BJ, Nagel IM, Goris MG, Hartskeerl RA, Grobusch MP. Leptospirosis in SubSaharan Africa: a systematic review. International Journal of Infectious Diseases. 2014;28:47-64.

30. Bharti AR, Nally JE, Ricaldi JN, Matthias MA, Diaz MM, Lovett MA, et al. Leptospirosis: a zoonotic disease of global importance. The Lancet infectious diseases. 2003;3(12):757-71.

31. Karshima N, Pam V, Bobbo A, Obalisa A. Occurrence of Cysticercus bovis in cattle slaughtered at the Ibi slaughter house, Ibi local government area of Taraba state, Nigeria. J Vet Adv. 2013;3(3):130-4.

32. Cheruiyot $\mathrm{H}$, Onyango-Abuje J. Taeniasis and cysticercosis in Kenya-a review. Tropical animal health and production. 1984;16(1):29-33.

33. Ndazigaruye G, Mushonga B, Kandiwa E, Samkange A, Segwagwe BE. Prevalence and risk factors for brucellosis seropositivity in cattle in Nyagatare District, Eastern Province, Rwanda. Journal of the South African Veterinary Association. 2018;89(0):e1-e8.

34. Ntivuguruzwa JB, Kolo FB, Gashururu RS, Umurerwa L, Byaruhanga C, van Heerden H. Seroprevalence and Associated Risk Factors of Bovine Brucellosis at the Wildlife-Livestock-Human Interface in Rwanda. Microorganisms. 2020;8(10):1553.

35. Nzeyimana P, Habarugira G, Udahemuka JC, Mushonga B, Tukei M. Prevalence of bovine cysticercosis and age relationship at post-mortem in Nyagatare slaughterhouse. 2015.

36. Rottbeck R, Nshimiyimana JF, Tugirimana P, Düll UE, Sattler J, Hategekimana J-C, et al. High prevalence of cysticercosis in people with epilepsy in southern Rwanda. PLoS Negl Trop Dis. 2013;7(11):e2558.

37. Awah Ndukum J, Kudi AC, Bradley G, Ane-Anyangwe I, Fon-Tebug S, Tchoumboue J. Prevalence of bovine tuberculosis in abattoirs of the littoral and Western highland regions of cameroon: a cause for public health concern. Veterinary Medicine International. 2010;2010.

38. Gervois M, Vaillant JM, Fontaine JF, Laroche G, Dubois G. Epidemiology of the human infection due to Mycobacterium bovis. Archivio Monaldi per la tisiologia e le malattie dell'apparato respiratorio. 1972;27(3):294-317.

39. Mfinanga S, Morkve O, Kazwala R, Cleaveland S, Sharp M, Kunda J, et al. Mycobacterial adenitis: role of Mycobacterium bovis, non-tuberculous mycobacteria, HIV infection, and risk factors in Arusha, Tanzania. East African Medical Journal. 2004;81(4):171-8. 
40. Fekadu F, Beyene TJ, Beyi AF, Edao BM, Tufa TB, Woldemariyam FT, et al. Risk Perceptions and Protective Behaviors Toward Bovine Tuberculosis Among Abattoir and Butcher Workers in Ethiopia. Frontiers in Veterinary Science. 2018;5(169).

41. Tsegay A, Tuli G, Kassa T, Kebede N. Seroprevalence and risk factors of brucellosis in abattoir workers at Debre Zeit and Modjo export abattoir, Central Ethiopia. BMC infectious diseases. 2017;17(1):101.

42. Luwumba D, Kusiluka L, Shirima G. Occupational hazards associated with human brucellosis in abattoir settings: A case study of Dodoma abattoir in Tanzania. 2019.

43. Nyokabi S, Birner R, Bett B, Isuyi L, Grace D, Güttler D, et al. Informal value chain actors' knowledge and perceptions about zoonotic diseases and biosecurity in Kenya and the importance for food safety and public health. Tropical Animal Health and Production. 2018;50(3):509-18.

44. Akkaya L, Alisarli M, Cetinkaya Z, Kara R, Telli R. Occurrence of Escherichia coli 0157: H7/0157, Listeria monocytogenes and Salmonella spp. in beef slaughterhouse environments, equipment and workers. Journal of Muscle Foods. 2008;19(3):261-74.

45. Milnes A, Stewart I, Clifton-Hadley F, Davies R, Newell D, Sayers A, et al. Intestinal carriage of verocytotoxigenic Escherichia coli 0157, Salmonella, thermophilic Campylobacterand Yersinia enterocolitica, in cattle, sheep and pigs at slaughter in Great Britain during 2003. Epidemiology \& Infection. 2008;136(6):739-51.

46. Molla B, Alemayehu D, Salah W. Sources and distribution of Salmonella serotypes isolated from food animals, slaughterhouse personnel and retail meat products in Ethiopia: 1997-2002. Ethiopian Journal of Health Development. 2003;17(1):63-70.

47. Vaira D, Holton J, Londei M, Beltrandi E, Salmon P, D'Anastasio C, et al. Campylobacter pylori in abattoir workers: is it a zoonosis? The Lancet. 1988;332(8613):725-6.

48. Dean AS, Crump L, Greter H, Hattendorf J, Schelling E, Zinsstag J. Clinical manifestations of human brucellosis: a systematic review and meta-analysis. PLoS neglected tropical diseases. 2012;6(12):e1929.

49. Adler B, de la Peña Moctezuma A. Leptospira and leptospirosis. Veterinary microbiology. 2010;140(34):287-96.

50. Derrick E. " Q" Fever, a New Fever Entity: Clinical Features, Diagnosis and Laboratory Investigation. Medical Journal of Australia. 1937;2(8).

51. Esmaeili S, Naddaf SR, Pourhossein B, Shahraki AH, Amiri FB, Gouya MM, et al. Seroprevalence of brucellosis, leptospirosis, and Q fever among butchers and slaughterhouse workers in south-eastern Iran. PloS one. 2016;11(1).

52. Nabukenya I, Kaddu-Mulindwa D, Nasinyama GW. Survey of Brucella infection and malaria among Abattoir workers in Kampala and Mbarara Districts, Uganda. BMC public health. 2013;13(1):901.

53. Swai ES, Schoonman L. Human brucellosis: seroprevalence and risk factors related to high risk occupational groups in Tanga Municipality, Tanzania. Zoonoses and public health. 2009;56(4):1837. 
54. Grange J, Collins C. Bovine tubercle bacilli and disease in animals and man. Epidemiology \& Infection. 1987;99(2):221-34.

55. Abiayi E, Inabo H, Jatau E, Makinde A, Sar T, Ugbe D, et al. Knowledge, attitudes, risk factors and practices (KARP) that favor Leptospira infection among abattoir workers in North Central Nigeria. Asian J Epidemiol. 2015;8(4):104-13.

56. Ismaila U, Rahman HA, Saliluddin S. Knowledge on bovine tuberculosis among abattoir workers in Gusau, Zamfara State, Nigeria. International Journal of Public Health and Clinical Sciences. 2015;2(3):45-58.

57. Minagri MoAaAR. Annual Report 2018 - 2019 Kigali, Rwanda MINAGRl; 2019 November 2019.

58. Worldmeter. Rwanda Demographics. Population of Rwanda (2020) 2020 [cited 2020 October 5, 2020]. Available from: https://www.worldometers.info/demographics/rwanda-demographics/.

59. Dohoo IR, Martin SW, Stryhn H. Veterinary epidemiologic research. Charlotte, P.E.I.: VER, Inc.; 2009.

60. Chatikobo P, Manzi M, Kagarama J, Rwemarika J, Umunezero O, editors. The prevalence of bovine brucellosis in milking dairy herds in Nyagatare and its implications on dairy productivity and public health. 3rd International Conference on Appropriate Technology November 12-15, 2008; 2008; Kigali, Rwanda

61. A language and environment for statistical computing. [Internet]. 2020. Available from: http://www. R-project.org/.

\section{Figures}




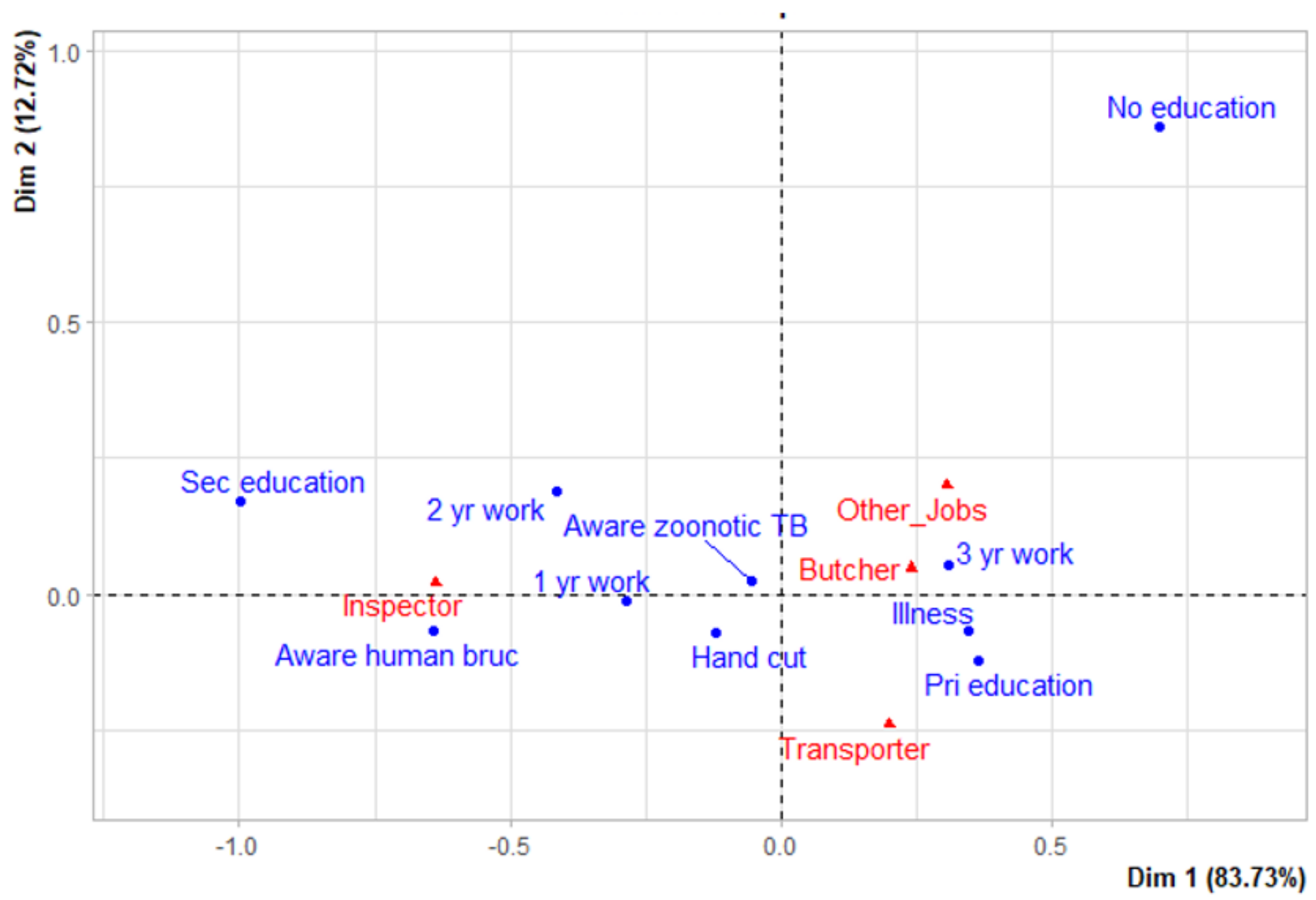

\section{Figure 1}

A symmetric biplot of the first two axes of the correspondence analysis illustrating the association of potential risk factors related to zoonotic brucellosis and zoonotic tuberculosis among workers in six abattoirs in Rwanda 


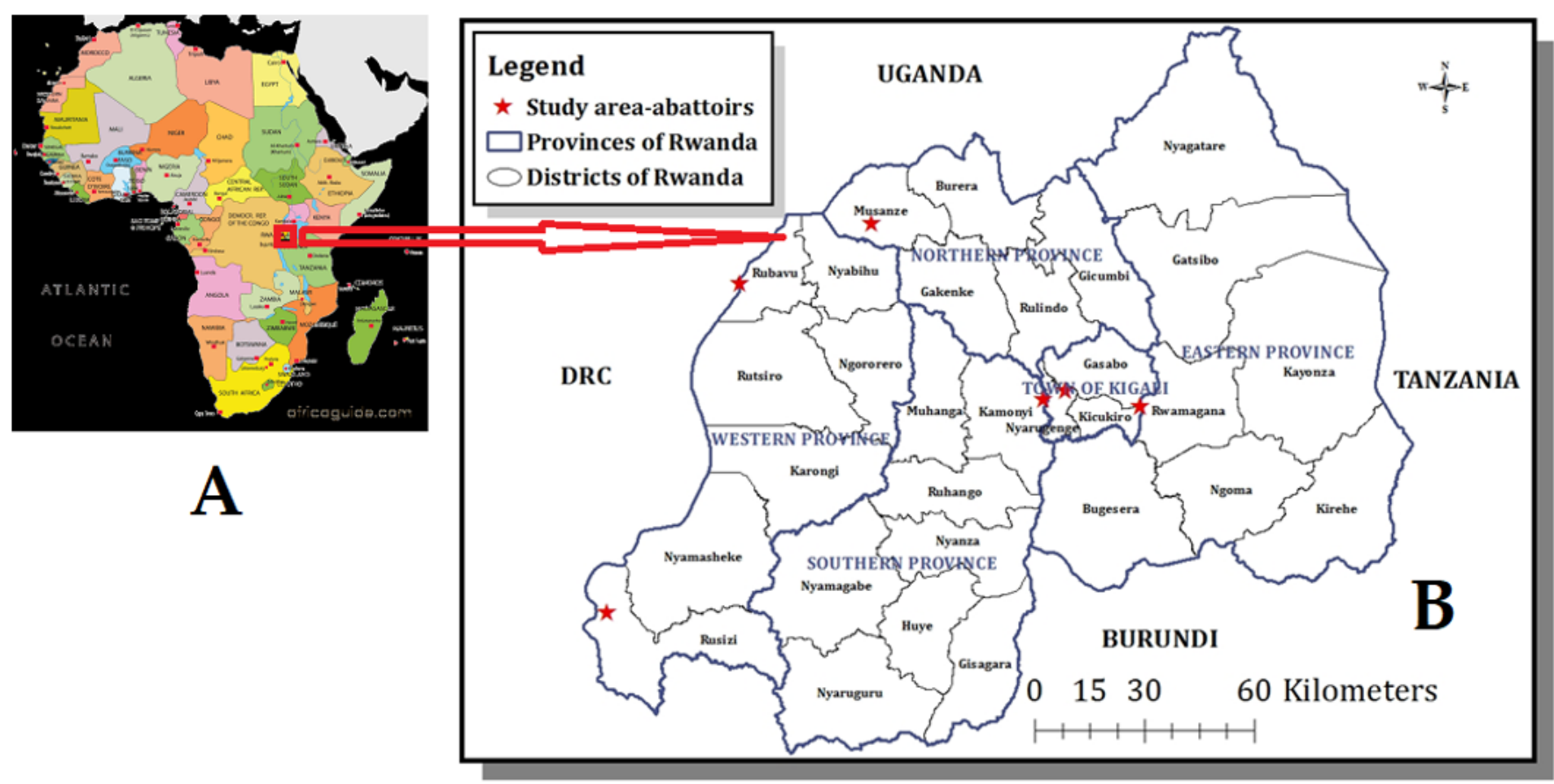

Figure 2

Maps of (A) Africa with a red rectangle showing the location of Rwanda on the continent, (B) Rwanda showing the districts with red asterixs showing the abattoirs that were visited in this study

\section{Supplementary Files}

This is a list of supplementary files associated with this preprint. Click to download.

- Supplementarymaterials.zip 